\title{
The Role of Medical Students in Responding To COVID-19: Identifying and Addressing Vital Deficiencies
}

\author{
Nick N. Maizlin $^{1, *} \quad$ | Kaveh Farrokhi ${ }^{1, *} \quad$ | Mike Ding ${ }^{1}$
}

${ }^{1}$ Schulich School of Medicine and Dentistry, Western University, London, Ontario,

Canada

\section{Correspondence}

Nick N. Maizlin

Email: nickmaizlin@gmail.com

\section{Publication Date}

September 23, 2020

MJM 2020 (18) 8

\section{McGill}

\section{Journal of Medicine}

\section{www.mjmmed.com}

\section{(c) (i) (2) (2)}

This work is licensed under a Creative Commons BY-NC-SA 4.0 International License.

\section{ABSTRACT}

To address the shortage of personal protective equipment (PPE) that occurred as a result of Coronavirus disease 2019 (COVID-19), three firstyear medical students at Western University developed an initiative to deliver handmade gowns to primary care providers in London, Ontario, Canada. They partnered with the local branch of the Canada Sews organization to sew the gowns, and created a gown order form which was distributed in the community. Following gown delivery by the authors, an optional feedback form was sent to the gown recipients for quality assurance purposes. As of June 10, 2020, 411 gowns had been delivered to medical and dental locations, long-term care homes, emergency shelters, and pharmacies. Feedback from the recipients indicated that the gowns were comfortable to wear and consistently useful to primary care practices. The successful execution of the initiative within several weeks of its inception, the delivery of more than 400 gowns over the period of approximately one month, and the positive feedback from the gown recipients, indicates that medical students can play an important role during the COVID-19 pandemic, and other periods of crisis, even outside of clinical settings. Specifically, they are able to demonstrate the qualities of leadership, collaboration, and advocacy to spearhead initiatives to fulfill unmet community needs. They are also uniquely situated to help their communities due to factors such as the skills and knowledge they have attained in their academic training. Thus, the ability of medical students to assist primary care providers should be taken into consideration for future pandemics.

\section{KEYWORDS}

COVID-19, medical students, role, personal protective equipment (PPE) 


\section{1 | INTRODUCTION}

The COVID-19 pandemic disrupted many institutions and presented them with unanticipated challenges. Hospitals and other medical facilities experienced a severe shortage of personal protective equipment (PPE) (1-3), which is crucial for protecting healthcare workers from exposure to contaminated bodily fluids from patients $(4,5)$. Educational institutions, including universities, were also affected by the pandemic, and forced to transition to online learning.

Among the individuals impacted were medical students, who, in many cases, were relegated to learning from home and had in-person clinical learning cancelled due to factors such as administrative concern for their safety and potential to further spread the disease (6-8). Wishing to help their communities, many medical students turned to organizing community initiatives such as babysitting, grocery delivery, and PPE drives for their fellow healthcare workers operating on the front lines of the COVID-19 pandemic $(9,10)$.

One such initiative was organized by three first-year medical students (the authors) at the Schulich School of Medicine and Dentistry at Western University in London, Ontario, Canada. While many community initiatives arose for the creation of facemask PPE for community and healthcare worker use, there was no known established initiative for creating and delivering protective gowns. To address this unmet need, the authors partnered with the local branch of the Canada Sews organization and organized the delivery of handmade gown PPE to primary care providers in the city. Gowns are critical in protecting healthcare workers interacting with potential COVID-19 patients $(3,11,12)$, and are one of the most commonly used PPE types in regular hospital use (12). They have experienced a surge in demand by healthcare workers alongside other PPE as a result of COVID-19 (1).

The limited literature available on the role of medical students during pandemics primarily focuses on their potential contributions in clinical settings (6,1315). Thus, this article examines the initiative by the Schulich medical students to deliver handmade gown
PPE, and the results achieved by it, including the number of gowns delivered and the feedback received for the initiative. The success of this initiative is used to elucidate the impact that medical students can have on their local communities outside of clinical settings during critical situations such as the COVID-19 pandemic.

\section{2 | INITIATIVE METHODS}

When the COVID-19 pandemic began, the almost immediate shortage of PPE in the London, Ontario community became evident. To create an initiative to help address this, the authors contacted local healthcare and community organizations (London-Middlesex Primary Care Alliance and Canada Sews) to assess community needs. Discussions illuminated that although there already were community initiatives to create homemade PPE (in particular, facemasks) by various organizations, there were no established programs for creating and delivering handmade protective gowns. As a result, the authors took on the role of delivering the sewn gowns to primary healthcare facilities in need throughout London, Ontario.

An online order form was created via Google Forms by the authors to collect orders for the gowns (Fig 1). The order form was distributed by the LondonMiddlesex Primary Care Alliance and Canada Sews via email. Additionally, social media platforms including Twitter were used to help raise awareness for the initiative.

The organizations that placed orders for gowns were categorized as "clinical" (walk-in clinics, hospitals), "dental" (including dentists, dental hygienists, endodontics), "long-term care facilities", "social support" (consisting of emergency shelters, hospices, or mental health services) and "other" which encompasses organizations including midwives, pharmacies, and businesses. Data was collected on the recipients in each category, and a 2-way ANOVA with Tukey's post hoc test was used for statistical analysis of the gown orders by the different types of organizations.

The gown order information was communicated by 
If you have any questions, please contact us at:

canadasewsgowns@gmail.com

* Required

Name of organization/clinic *

Your answer

Contact name (first and last name) *

Your answer

Contact email *

Your answer

Contact phone number *

Your answer

Number of gowns required (additional gowns may be ordered in the future based on available supply) *

Choose

What size gowns would you prefer? (Please note that we may not be able to accommodate all requests)
$\square$ small
$\square$ Med
$\square$ Large

Delivery address *

Your answer

Specific delivery instructions (if necessary, such as if the dropoff location is in a large complex)

Your answer

Submit

FIGURE 1 Online order form for requesting handmade gown PPE

the authors to Canada Sews members, who sewed gowns based on the requested amounts. To provide recommendations on the fabric required for the gowns, the authors conducted a review of available literature, which indicated that isolation gowns should be a polyester-cotton mix or full polyester (12). Initially,

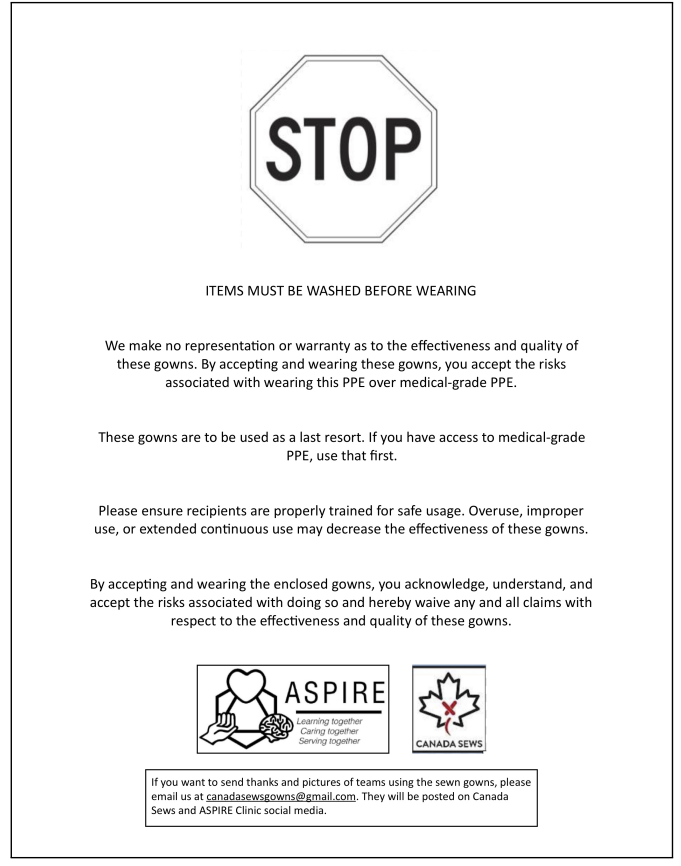

FIGURE 2 The disclaimer form attached to all delivered handmade gown PPE

gowns were made from donated or bought material. Later, as additional material became available, the sewers transitioned to making gowns from material provided by the company LacMac, which makes medicalgrade isolation gowns.

Following the completion of the gown sewing, the gowns were quarantined for approximately three days to ensure that there would be no COVID-19 virus contamination on the materials; this decision was based on the then-available literature $(16,17)$. Following quarantine, the authors delivered the gowns to the requesting locations, indicating that the gowns should be washed before use. Orders were delivered on a first-come, firstserve basis. The authors performed the work on a volunteer basis and the gowns were provided free of charge to the recipients.

To help ensure legal coverage for the initiative and protection from legal liability, the authors contacted lawyers at a local law firm, who provided assistance in creating a disclaimer form that was attached to the de- 
livered gowns. The form explicitly stated that the gowns were not medical-grade, were meant to be used only as a last resort in the absence of medical-grade PPE, and reminded the user to practice safe donning and doffing of the gown to ensure maximal protection (Fig 2).

Thank You notes were also attached to the delivered gowns as a way to increase morale among the healthcare workers receiving them.

To evaluate the benefit of the delivered gowns for the organizations that received them, and to refine the gowns for future deliveries, an optional online feedback form was created by the authors via Google Forms for gown recipients to complete (Fig 3).

The feedback included questions such as whether the gowns were useful to the recipient's practice, were comfortable to wear, and if the recipients had additional suggestions for gown improvement or general

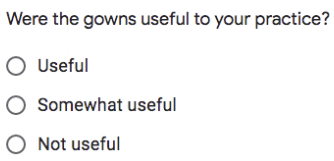

How would you rate the experience of using the gowns? ( 3 is neutral)

$\begin{array}{lllllll} & 1 & 2 & 3 & 4 & 5 & \\ \text { Very negative } & \bigcirc & \bigcirc & \bigcirc & \bigcirc & \bigcirc & \text { Very positive }\end{array}$

Was the gown material comfortable to wear?

Comfortable

Neutral

Uncomfortable

Do you have any suggestions for improving the gowns?

Your answer

Any additional comments regarding the delivered gowns?

Your answer

Submit

FIGURE 3 Optional online feedback form for gown recipients comments. Additional informal feedback was provided by gown recipients via email or in-person on subsequent deliveries.

\section{3 | INITIATIVE RESULTS}

The idea of the initiative was conceived at the end of March 2020, days after the provincial pandemic shutdown order. After initially establishing supply chain logistics and an in-take system for gown orders, the first order for the gowns was received on April 21st, 2020. The first shipment of gowns was delivered to the requesting location on May 7, 2020.

From April 21st, 2020 to June 10th, 2020, 44 total unique orders had been placed, and 24 orders had been fulfilled; by this date, 765 gowns had been requested, and 411 gowns had been delivered (Fig 4a). In terms of the total unique orders from each of the recipient categories, the clinical category placed the most orders $(n=12)$, followed by dental $(n=10)$ and other $(n=10)$, long-term care facilities $(n=7)$, and social support $(n=5)$ (Fig 4b). Dental locations requested the greatest number of gowns (177), followed by clinical (169), long-term care facilities (160), other (149), and social support (110) (Fig 5a). On average, long-term care facilities requested the highest number of gowns per order (mean=22.86 $\mathrm{SD}=7.56)$ and the clinical locations ordered the lowest number of gowns per order (mean=14.08 SD=7.82); however, this did not reach statistical significance as measured by ANOVA (Fig 5b).

At the time of writing, 13 feedback responses had been provided. The anonymous feedback provided by the gown recipients consistently indicated that the gowns were comfortable to wear and were useful to primary care practice. One response indicated that several of the gowns delivered were too large and that the gown recipients wished to have more options regarding sizing. The comments provided were consistently positive regarding the importance and value of the initiative (example responses are shown in Table 1). 
a)

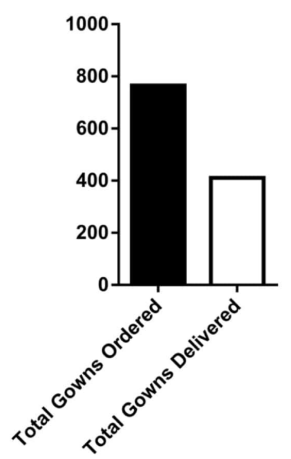

b)

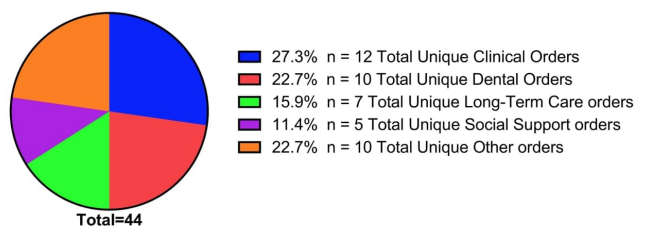

FIGURE 4 a) As of June 10, 2020, the total number of gowns requested were 765, with 411 gowns delivered. b) The total number of unique orders placed as of June 10, 2020 (duplicate orders by the same organization or individual were excluded). Orders were categorized as clinical, dental, long-term care, social support, or other.

a)

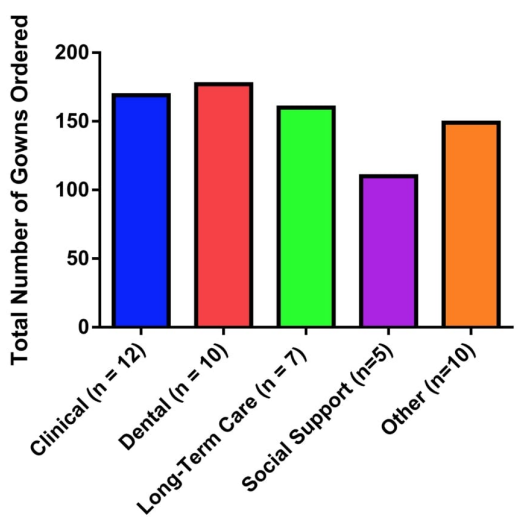

b)

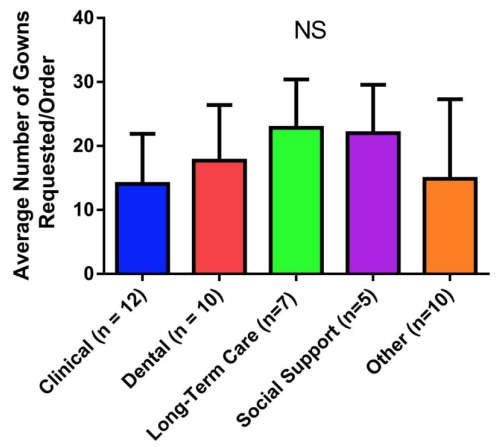

FIGURE 5 a) Total gown orders by clinical, dental, long-term care, social support, and other organizations. b) Average number of gowns requested per order of each category of organization. Data expressed as mean + standard deviation.

\section{I DISCUSSION OF INITIATIVE RESULTS}

There is limited literature available discussing the role of medical students during pandemics. During the 1918 influenza pandemic, some medical students were provided more responsibility by being allowed to graduate early, and had expedited board examinations to address the medical staff shortage present at the time (15). During the COVID-19 pandemic, some areas also al- 
lowed senior medical students to graduate early $(6,13)$. It is possible that fast-tracking medical students into full MDs during the pandemic may have provided them with additional medical training that they would not have received in normal clinical practice (14). However, working on the front lines can place medical students at an increased risk for contracting the disease that they are trying to contain (14), an issue raised during the COVID-19 pandemic (6). Removing the students from in-person clinical practice, while cognizant of the medical students' (and potentially others') safety, can lead to backlash from the medical students. For example, the removal of medical students from the wards during the SARS epidemic in Toronto caused frustration among them as it adversely impacted their education and ability to conduct research (18).

Another option for medical students wishing to assist fellow healthcare workers is to help outside of clinical settings, as described in the initiative discussed in this paper to deliver gown PPE to primary care providers in London, Ontario. The handmade gowns made by the local sewers, while not a substitute for medical-grade gowns, may be able to provide some form of protection for the gown recipients in the absence of other PPE, assuming proper donning and doffing procedures are followed.

Over 400 gowns were delivered from May 7, 2020 to June 10, 2020 to locations including medical clinical centers, dental centers, long-term care homes, pharmacies, and emergency shelters. This indicates the broad range of institutions that the medical students were able to reach with the gown initiative. Fifty percent of the orders were placed by dentistry and clinical centers, which also comprised $50 \%$ of the gown requests. The average number of gowns per order was highest for long-term care and social support locations, with clinical centers having the lowest average number of gowns per order. Although this finding was not statistically significant, it might reflect the higher number of staff per facility in long-term care and social support facilities as compared to clinical locations. It may also reflect the lesser number of long-term care and social support facilities in the area, or a lesser need among them for additional gown PPE (due to an adequate facility supply); however, this is difficult to determine as the order form may not have reached all long-term care facilities.

\begin{tabular}{llll}
\hline Question & Response 1 & Response 2 & Response 3 \\
\hline $\begin{array}{l}\text { Were the gowns useful } \\
\text { to your practice? }\end{array}$ & Useful & Useful & Useful \\
\hline $\begin{array}{l}\text { How would you rate the } \\
\text { experience of using the }\end{array}$ & 5 & 4 & 5 \\
$\begin{array}{l}\text { gowns? (3 is neutral) } \\
\text { Was the gown material } \\
\text { comfortable to wear? }\end{array}$ & Comfortable & Comfortable & Comfortable \\
\hline $\begin{array}{l}\text { Do you have any } \\
\text { suggestions for } \\
\text { improving the gowns? }\end{array}$ & Not at this time & - & Keep up the great work, \\
\hline $\begin{array}{l}\text { Any additional comments } \\
\text { regarding the delivered } \\
\text { gowns? }\end{array}$ & $\begin{array}{l}\text { Awesome work that your } \\
\text { team has done in order } \\
\text { to make our jobs easier. }\end{array}$ & $\begin{array}{l}\text { We were very thankful to } \\
\text { have received them, and I } \\
\text { was quite surprised at }\end{array}$ & $\begin{array}{l}\text { Excellent, Used daily, } \\
\text { greatly appreciated, } \\
\text { Thank you, THANK }\end{array}$ \\
\hline
\end{tabular}

TABLE 1 Sample responses to the feedback forms sent out to gown recipients. 
Responses to the quality control feedback form consistently indicated that the gowns were comfortable to wear and proved useful in everyday practice. One response to the feedback form included a comment stating that "We were very thankful to have received [the gowns], and I was quite surprised at how well they were constructed and sewn". Another comment praised the work of the gowns team and indicated that the gowns had "[made] our jobs easier". Comments, such as the one which requested more flexibility in gown sizing, play an important role in the quality improvement process and were communicated to the sewers. The feedback form was made optional as to not put an additional burden on healthcare providers. The form also did not assess whether the recipients felt that the gowns contributed to their safety; although subsequent gowns may have utilized material used by professional PPE producers (i.e., LacMac), they were not medical-grade PPE and were meant to be used as a last resort.

The results of the feedback form indicate that this initiative was greatly beneficial to the individuals that received the gowns. Moreover, many healthcare workers, particularly dentists, work in an environment in which they are exposed to aerosolized patient fluids (which may have been contaminated with COVID-19). Thus, having gown PPE may have been particularly important for them, as indicated by the significant number of gown orders by dental locations.

Ultimately, the success of this project was indicated by the large number of gowns delivered within a short period of time (considering that gowns take significantly longer to sew than masks), and the consistently positive feedback regarding the usefulness of the gowns from the gown recipients. The fact that the initiative was successfully executed within the period of a month further highlights its effectiveness and importance, particularly during a period when PPE was in short supply.

Some challenges were encountered in conducting this initiative, including:

- Planning: When the initiative first began, it was difficult to estimate the number of gowns that would be requested in each individual order, and the rate at which sewers would be able to supply the gowns. To address this issue, additional gowns were offered to be delivered, once supply was available, to locations that had made initial orders and required more gowns. After several deliveries, there was a better understanding of the number of gowns that could be provided for each order, allowing for more effective planning for further orders.

- Quality control: The optional nature of the feedback form limited the number of individuals that responded to it. However, the informal feedback that was received either by email or in-person was also taken into account.

\section{5 | THE ROLE OF MEDICAL STU- DENTS}

This initiative demonstrates that medical students can help make an important and positive impact during periods of crisis (such as the COVID-19 pandemic) even outside of clinical settings. For one, they are able to help address a real and urgent need in their community that may not have been effectively acted upon previously. In the initiative discussed in this paper, medical students were able to develop an initiative to create and distribute gown PPE, which was not a service that had been effectively organized in the area at the beginning of the COVID-19 pandemic, despite the high demand for all types of PPE. Even more, they went a step further and created a feedback form to help adapt the initiative to the needs of the recipients. Other groups of medical students took charge in providing services such as grocery delivery for families of healthcare workers that were busy in the hospital as a result of the pandemic $(9,10)$, which were initiatives that also did not exist when the COVID-19 pandemic began.

The gown initiative also demonstrates that medical students are effectively able to exemplify the qualities of leadership, collaboration, and advocacy (collectively known in Canada as the CanMEDS roles (19), which they are required to demonstrate for admission into Canadian medical schools) to effectively execute a solution to 
an identified need. In this case, medical students were able to spearhead an initiative to fill a void in the delivery of PPE by establishing connections with clinical and nonclinical personnel, beginning gown deliveries within a month of the initiative's inception, and creating a system (via a feedback form) to ensure a quality assurance process in the project and that it was beneficial to the community. The embodiment of these qualities by medical students is also evident in the development of other aforementioned medical student-led community initiatives, indicating that they are able to work with their communities to execute large-scale projects.

Ultimately, medical students are in an effective position to help their communities. They have undergone police screening and have exposure to clinical settings and staff, allowing them to establish connections with hospitals and other healthcare organizations more readily than non-medical students (20). They are also highly motivated to assist their communities, as evidenced by the number of initiatives begun by medical students during the COVID-19 pandemic, and their participation in prior crisis response groups (14). During the COVID-19 pandemic, some medical students even joined alreadyestablished efforts for contact tracing and mental health lines in their communities; their clinical expertise and training (however limited) can enhance the help they are able to provide in such services, such as teasing out the nuances of patient histories and providing empathy and reassurance for patients. For future potential pandemics, as indicated by Herman et al., it is important to pre-plan the roles that medical students can perform (14), which, as shown with this initiative, can be varied and self-perpetuated.

\section{6 | CONCLUSION}

With the rising cases of COVID-19 around the world, many initiatives were created to help address the issues caused by the pandemic. Medical students played a large role in some of these initiatives, including the one outlined in this paper. In this initiative, three first-year medical students from Western University worked to deliver handmade gowns in London, Ontario via collaboration with local healthcare and community organizations to fulfill a shortage of gown PPE that was not being met by other community initiatives. The initiative's successful execution within a month of its inception, over 400 gowns delivered over the space of approximately one month, and positive responses from gown recipients, indicates that medical students can effectively assist their communities during major pandemics and other crises even outside of clinical settings. They are able to effectively demonstrate qualities such as leadership, collaboration, and advocacy in working with each other and local organizations to make a direct impact in the community. Thus, the tangible and much-needed assistance that they can provide should be supported and taken into consideration in future pandemics and other periods of crisis.

\section{Acknowledgements}

The authors express their gratitude and appreciation to all the Canada Sews volunteers and sewers, as well as the London-Middlesex Primary Care Alliance for their invaluable assistance and support in realizing and executing the handmade gowns initiative.

\section{REFERENCES}

1. Livingston E, Desai A, Berkwits M. Sourcing Personal Protective Equipment During the COVID-19 Pandemic. JAMA. 2020 May 19;323(19):1912-4.

2. Ranney ML, Griffeth V, Jha AK. Critical Supply Shortages - The Need for Ventilators and Personal Protective Equipment during the Covid-19 Pandemic. N Engl J Med. 2020 Apr 30;382(18):e41.

3. Rational use of personal protective equipment (PPE) for coronavirus disease (COVID-19): interim guidance. WHO [Internet]. 2020 Mar 19 [cited 2020 May 29]. Available from: https://apps.who.int/iris/bitstream/handle/10665/331498/WHO2019-nCoV-IPCPPE_use-2020.2-eng.pdf

4. Casanova L, Alfano-Sobsey E, Rutala WA, Weber DJ, Sobsey M. Virus Transfer from Personal Protective Equipment to Healthcare Employees' Skin and Clothing. Emerg Infect Dis. 2008 Aug;14(8):1291-3.

5. Honda H, Iwata K. Personal protective equipment and improving compliance among healthcare workers in high-risk settings. Curr Opin Infect Dis. 2016 Aug;29(4):400-406. 
6. Kalet AL, Jotterand F, Muntz M, Thapa B, Campbell B. Hearing the Call of Duty: What We Must Do to Allow Medical Students to Respond to the COVID-19 Pandemic. WMJ. 2020;119(1):6-7.

7. Rose S. Medical Student Education in the Time of COVID-19. JAMA. 2020 Jun 2;323(21):2131-2.

8. Joint Statement to all Ontario Medical Students. Council of Ontario Faculties of Medicine [Internet]. [cited 2020 May 28]. Available from: https://www.schulich.uwo.ca/about/covid_19_updates/docs /Joint_Statement_to_all_Ontario_Medical_Students_Final_Western _APRIL_16.pdf.

9. Ferrel MN, Ryan JJ. The Impact of COVID-19 on Medical Education. Cureus. 2020 Mar 31;12(3):e7492.

10. Krieger P, Goodnough A. Medical Students, Sidelined for Now, Find New Ways to Fight Coronavirus. The New York Times [Internet]. 2020 Mar 23 [cited 2020 Jun 8]; Available from: https://www.nytimes.com/2020/03/23/health/medical-studentscoronavirus.html

11. Jefferson T, Mar CD, Dooley L, Ferroni E, Al-Ansary L, Bawazeer G. Physical interventions to interrupt or reduce the spread of respiratory viruses: a Cochrane review. Health Technol Assess. 2010;14(34):129.

12. Kilinc FS. A Review of Isolation Gowns in Healthcare: Fabric and Gown Properties. J Eng Fiber Fabr. 2015 Sep 1;10(3):155892501501000320.

13. Harvey A. Covid-19: medical schools given powers to graduate final year students early to help NHS. BMJ [Internet]. 2020 Mar 26 [cited 2020 Jun 6];368. Available from: https://www.bmj.com/content/368/bmj.m1227

14. Herman B, Rosychuk RJ, Bailey T, Lake R, Yonge O, Marrie TJ. Medical Students and Pandemic Influenza. Emerg Infect Dis. 2007 Nov;13(11):1781-3.

15. Starr I. Influenza in 1918: Recollections of the Epidemic in Philadelphia. Ann Intern Med. 2006 Jul 18;145(2):138-40.

16. van Doremalen N, Bushmaker T, Morris DH, Holbrook MG, Gamble A, Williamson BN, et al. Aerosol and Surface Stability of SARS-CoV-2 as Compared with SARS-CoV-1. NEJM. $2020 \mathrm{Apr}$ 16;382(16):1564-7.

17. Kampf G, Todt D, Pfaender S, Steinmann E. Persistence of coronaviruses on inanimate surfaces and their inactivation with biocidal agents. J Hosp Infect. 2020 Mar 1;104(3):246-51.

18. Clark J. Fear of SARS thwarts medical education in Toronto. BMJ. 2003 Apr 12;326(7393):784.

19. CanMEDS Framework. Royal College Of Physicians and Surgeons of Canada [Internet]. [cited 2020 June 1]. Available from: http://www.royalcollege.ca/rcsite/canmeds/canmedsframework-e

20. Stokes DC. Senior Medical Students in the COVID-19 Response: An Opportunity to Be Proactive. Acad Emerg Med. 2020 Apr;27(4):343-5. 